\title{
Outcome of donor and recipient sex match versus mismatch in stem cell transplant procedure
}

\author{
Natasha Ali*,1, Hayat Ullah², Mohammad Usman Shaikh \& Salman Naseem Adil ${ }^{3}$ \\ ${ }^{1}$ Associate Professor Haematology, Department of Pathology \& Laboratory Medicine/Oncology, Aga Khan University, Karachi, \\ Pakistan \\ ${ }^{2}$ Consultant Clinical Haematologist, Department of Oncology/Radiotherapy, Bolan Medical Complex Hospital, Quetta, Pakistan \\ ${ }^{3}$ Professor Haematology, Department of Pathology \& Laboratory Medicine/Oncology, Aga Khan University Karachi, Pakistan \\ *Author for correspondence: Tel.: +92 213486 1306; natasha.ali@aku.edu
}

\begin{abstract}
Aim: We determined the frequency of graft-versus-host disease (GvHD) and overall survival (OS) in sex matched vs mismatched transplant. Methods: Medical records were analyzed of patients undergoing transplant from 2004 to 2016. Variables included age, sex of patient and donor, indication, conditioning regimen, stem cell source, frequency of GvHD and OS. Results: We performed $n=162$ allogeneic stem cell transplants. The most common conditioning regimen was busulfan/cyclophosphamide $(n=64)$. There was no difference in the frequency of GvHD in both groups. The transplant related mortality was higher $(8.7 \%)$ in sex-mismatched transplants. The OS in both groups was similar. Conclusion: Our study showed higher transplant-related mortality in sex-mismatched transplant. There was no difference in GvHD and OS in both groups.
\end{abstract}

First draft submitted: 25 June 2019; Accepted for publication: 15 November 2019; Published online: 18 December 2019

Keywords allogeneic transplants • mismatch • sex

Hematopoietic stem cell transplant is a potential curative treatment option for benign and malignant hematological diseases [1]. The most critical factor in determining the outcome of transplant is based on the degree of human leucocyte antigen (HLA) disparity [2]. However, the development of morbidity and mortality secondary to transplant procedure depends on factors other than HLA matching as well. The preferred choice for 10/10 match is an HLAmatched sibling donor. In a developing country like Pakistan, where large family sizes are common, patients may have more than one HLA-matched sibling donor. Thus, in such circumstances, it is necessary to consider factors other than HLA typing for best possible outcome of procedure. These other factors include ABO compatibility, cytomegalovirus status, age of donor, sex and parity [3]. The factors found to be most debatable include sex and parity [4].

Several studies have demonstrated that recipient minor histocompatibility antigens ( $\mathrm{H}$ antigens) are the targets of donor $\mathrm{T}$ cells mediating graft-versus-host disease (GvHD) and graft versus leukemia (GvL) effect [5]. These minor $\mathrm{H}$ antigen peptides arise from cellular proteins of polymorphic genes that are different in recipient and donor. These differing peptides are presented to $\mathrm{CD}^{+}$and $\mathrm{CD}^{+}{ }^{+} \mathrm{T}$ cells of major histocompatibility complex 1 and 2, respectively [6]. The male H-Y antigen, part of the minor $\mathrm{H}$ antigen in humans, the expression of which is limited to hematopoietic cells, mainly leukemic cells, is responsible for the GvL effect. In the setting of a female donor to male recipient stem cell transplant, donor $\mathrm{T}$ cells encoding minor $\mathrm{H}$ antigens which are specific for genes on recipient $\mathrm{Y}$ chromosome may be present and subsequently lead to the GvHD and GvL effect. Genes on the Y chromosome encoding these $\mathrm{H}$ antigens have already been identified and their roles in GvHD and GvL are being investigated [7].

A review of literature has shown an increased risk of acute or chronic GvHD in sex-mismatch transplants $[8,9]$. Bross et al. published results of $\mathrm{n}=136$ patients in which the development of Grade II-IV acute GvHD was seen in $71 \%$ of patients who received a sex-mismatch transplant [10]. Similarly, Randolph et al. did a retrospective review in $\mathrm{n}=3238$ patients undergoing HLA-matched sibling donor transplant after receiving myeloablative regimen.

Future Medicine 
Statistically significant odds ratio was obtained in male patients receiving allografts from female donors for Grades II-IV acute GvHD and extensive chronic GvHD [11].

On the other hand, an increased incidence of GvHD in sex-mismatched transplants also leads to decreased risk of disease relapse, subsequently leading to increased overall survival (OS). Gratwohl et al. [12] has shown in a cohort of $\mathrm{n}=782$ patients with chronic myeloid leukemia in chronic phase that male recipients of female bone marrow or peripheral blood grafts are at higher risk of GvHD but decreased risk of disease recurrence, thus suggesting the importance of GvL effect.

At the Aga Khan University's (Karachi, Pakistan) bone marrow transplant unit, allogeneic and autologous stem cells transplants are being performed since 2004. Though we have previously published the initial outcome of stem cell transplant procedure for benign and malignant hematological diseases [13], the objective of this study was to determine the frequency of GvHD and the OS of patients who underwent a sex matched versus sex mismatched transplant.

\section{Materials \& methods}

All patients with nonmalignant and malignant hematological disorders with HLA-matched donors were selected for the procedure.

\section{Stem cell mobilization}

All donors were given granulocyte-colony stimulating factor at a dose of $5 \mu \mathrm{g} / \mathrm{kg}$ twice daily for 5 days prior to harvest. Patients whose donors were younger than 5 years old received bone marrow only as the stem cell source. A combination of peripheral blood and bone marrow stem cells were harvested in patients with aplastic anemia. Apart from this, the main source of stem cells was peripheral blood.

\section{Conditioning regimen}

All patients with $\beta$-thalassemia major, acute myeloid leukemia in first complete remission, chronic myeloid leukemia, biphenotypic leukemia and Philadelphia negative acute lymphoblastic leukemia received oral Busulfan $(4 \mathrm{mg} / \mathrm{day}$ for 4 days) and Cyclophosphamide $(60 \mathrm{mg} / \mathrm{kg} /$ day for 2 days) as conditioning chemotherapy until 2015, after which intravenous Busulfan $(3.2 \mathrm{mg} / \mathrm{kg} /$ day for 4 days) was used. Hyperchelation protocol was used in patients with class III $\beta$-thalassemia major. Total body irradiation $(1.5 \mathrm{cGY} \times$ twice a day) and Cyclophosphamide $(60 \mathrm{mg} / \mathrm{kg} / \mathrm{day}$ for 2 days) was used in patients with Philadelphia positive acute lymphoblastic leukemia, relapsed leukemia, FLT-3 positive acute myeloid leukemia and patients with one-antigen mismatch donors.

In aplastic anemia, antithymocyte globulin $(10 \mathrm{mg} / \mathrm{kg} / \mathrm{day}$ for 3 days $)$ and Cyclophosphamide $(50 \mathrm{mg} / \mathrm{kg} / \mathrm{day}$ for 4 days) was used. We used post-transplant cyclophosphamide on days +3 and $+4(50 \mathrm{mg} / \mathrm{kg})$ in patients who underwent a haploidentical transplant procedure.

\section{Infectious disease prophylaxis}

Patients were admitted in protective isolation equipped with a high efficiency particulate air filter, positive pressure and laminar airflow ventilation. Standard prophylaxis with Ciprofloxacin $(500 \mathrm{mg}$ twice daily or $20-30 \mathrm{mg} / \mathrm{kg} / \mathrm{two}$ divided doses), Voriconazole (200 mg once daily or $6 \mathrm{mg} / \mathrm{kg} /$ day) and Valaciclovir (500 mg twice daily or $10 \mathrm{mg} / \mathrm{kg}$ twice daily) was started in all patients on day 5 . All patients were provided with a neutropenic diet.

\section{Graft-versus-host disease prophylaxis}

Intravenous cyclosporine was started on day- 1 and drug levels were monitored. Optimum adult range was 200$250 \mathrm{ng} / \mathrm{dl}$. For pediatric patients, levels were maintained between $150-200 \mathrm{ng} / \mathrm{dl}$. Methotrexate $\left(15 \mathrm{mg} / \mathrm{m}^{2}\right)$ was administered on day +1 , while $10 \mathrm{mg} / \mathrm{m}^{2}$ was given on days $+3+6$. In haploidentical transplants, dual immunosuppression was given with mycophenolate mofetil $(15 \mathrm{mg} / \mathrm{kg}$ twice daily) and tacrolimus $(0.12 \mathrm{mg} / \mathrm{kg}$ in two divided doses). Irradiated blood products were used throughout admission. Grading of GvHD was done according to the Glucksberg classification.

\section{Statistical analysis}

All the data was entered on SPSS version 22 (SPSS Inc., IL, USA) for computing means, standard deviation and range of all descriptive variables. $\chi^{2}$ was used to compare variables and Kaplan-Meier survival curves were used to determine OS. The level of significance was 0.05 . 
Table 1. Indications and stem cell sources according to sex match/mismatch status.

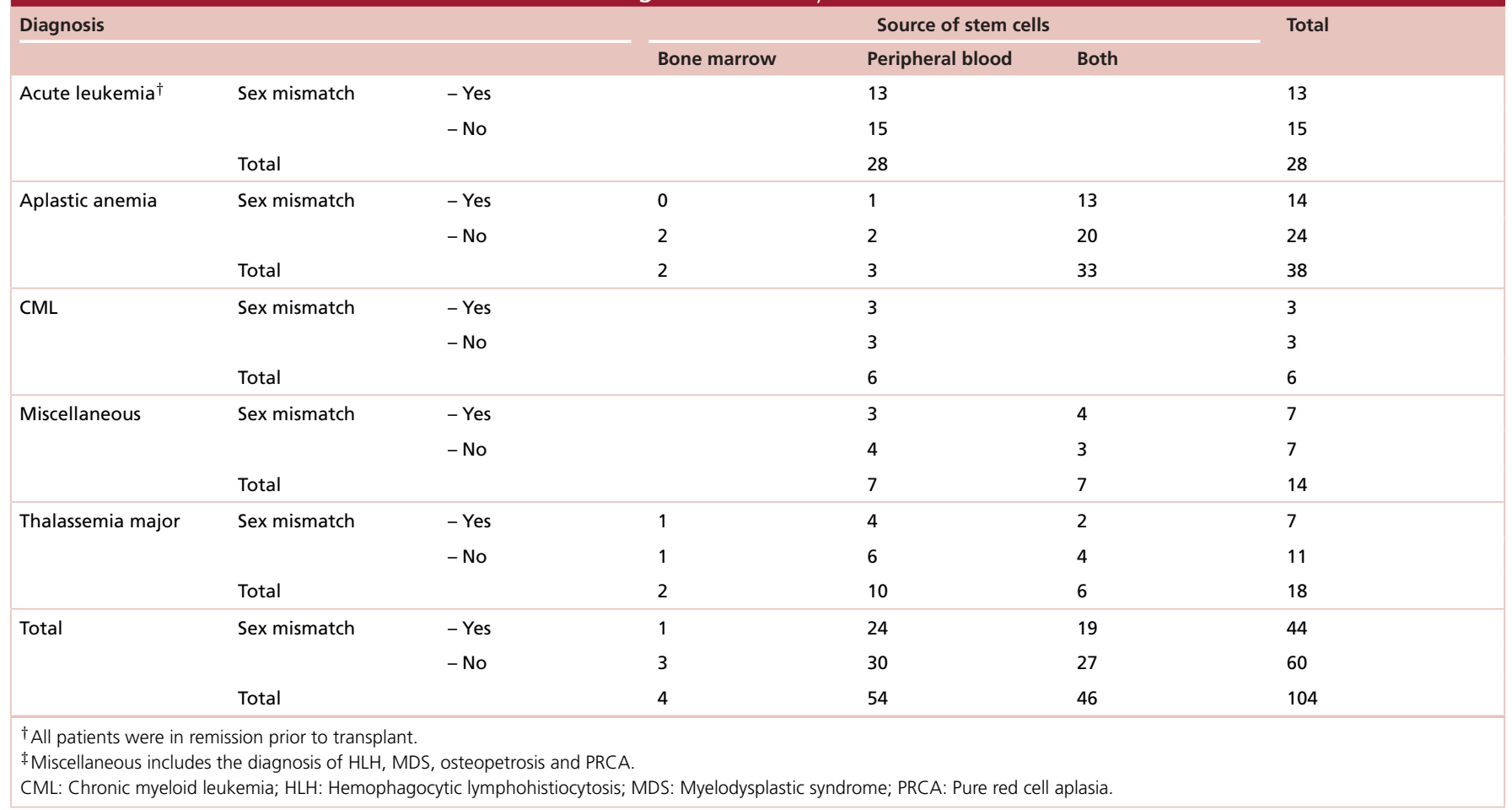

\section{Table 2. Direction of sex mismatch.}

\begin{tabular}{|l|l|}
\hline Donor sex & Number $(\mathbf{n})$ \\
\hline Male donor (any recipient) & $\mathbf{5 2}$ \\
\hline Male:Male & 41 \\
Male:Female & 11 \\
Total & 52 \\
\hline Female donor (any recipient) & $\mathbf{5 2}$ \\
\hline Female:Male & 33 \\
Female:Female & 19 \\
\hline Total & $\mathbf{5 2}$ \\
\hline
\end{tabular}

\section{Results}

From April 2004 till December 2016, we had performed 162 allogeneic transplants. This included 118 males and 44 females. The median age \pm standard deviation (range) was $18 \pm 13.12$ (2-59 years). There were 92 patients in the adult age group and $n=70$ pediatric patients (the indications and stem cell source for transplant with respect to sex is given in Table 1). The most frequently used conditioning regimen was busulfan/cyclophosphamide in 64 patients, followed by antithymocyte globulin and cyclophosphamide in 56 patients. All patients received a myeloablative-conditioning regimen. Eighteen patients received cyclophosphamide and total body irradiation as part of the conditioning regimen. Haploidentical protocol was used in five patients. Peripheral blood was used as a source of stem cells in 94 patients, while bone marrow stem cells were used in 23 procedures. A combination of bone marrow and peripheral blood stem cells was used in 45 patients.

We performed 115 (71\%) same sex transplants and 47 (29\%) sex-mismatched procedures. The results showed that GvHD was present in 23 patients (14.6\%) in the same sex group while 20 patients (12.7\%) developed GvHD in the sex-mismatched group $(\mathrm{p}=0.7986)$. The direction of mismatch is given in Table 2.

Multivariate analysis was performed between age, source of stem cells, GvHD, relapse of disease and presence of sex mismatch. None of the variables were found to be statistically significant.

The transplant related mortality (TRM) was calculated at day 100. The cumulative frequency of TRM was $5.8 \%$ in patients who received a sex-matched transplant, while it was $8.7 \%$ in patients who had a sex-mismatched 


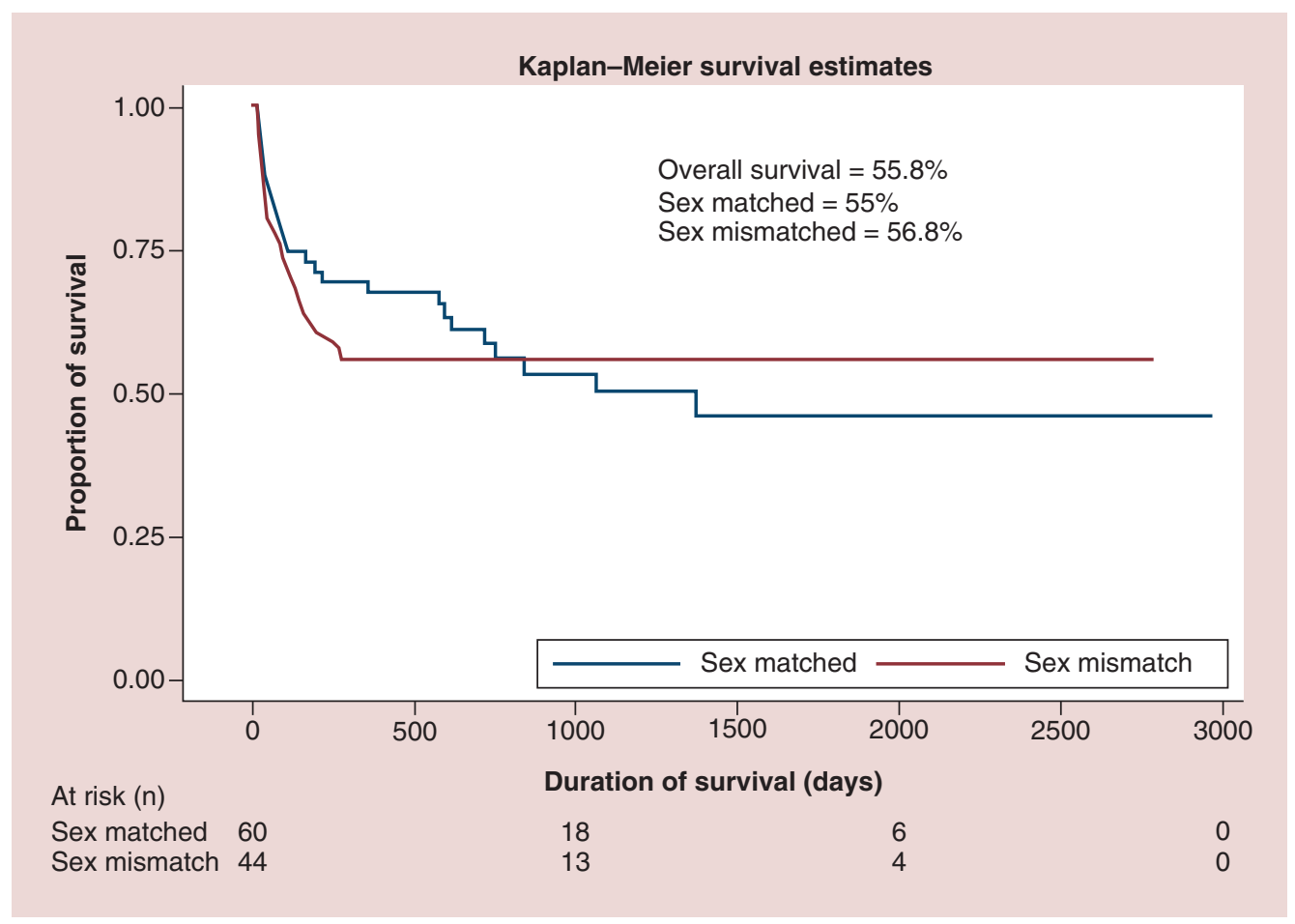

Figure 1. Kaplan-Meier survival curves for sex-matched versus sex-mismatched transplant.

donor $(\mathrm{p}<0.0001)$. The main causes of higher mortality in sex-mismatched transplant were hepatic and renal toxicity, sepsis and sinusoidal obstructive syndrome. Mortality due to disease relapse was present in $13 \%$ of patients, out of which 5\% was in the sex mismatch and 9\% in the sex-matched group. In patients who received a sex-matched transplant and developed GvHD, the cumulative frequency of TRM was $12.1 \%$ while those who received a sexmismatched transplant and developed GvHD, the cumulative frequency of TRM was $9 \%(p=0.16)$. In contrast, patients who received a sex mismatch transplant but did not develop GvHD, the cumulative frequency of TRM was $6.0 \%$ while those with same sex transplant who did not develop GvHD the TRM cumulative frequency was $8.0 \%(\mathrm{p}=0.08)$. The OS in both groups evaluated at 1 year was approximately $56 \%$ (Figure 1 ).

\section{Discussion}

This is the first study from Pakistan to determine the outcome of sex matched vs mismatch allogeneic transplants in benign and malignant hematological disorders. In our cohort, $95 \%$ of patients underwent the procedure with complete HLA matched donor while 5\% were one and/or two allele mismatched with their donors. Our results did not show a statistically significant correlation between the presence of GvHD and donor/recipient sex combination. These results are in contrast to previous studies which have reported that sex mismatch transplants have the highest odds of developing GvHD due to the GvL effect [14,15]. However Friedrich et al. reported no evidence of chronic GvHD in young donors who received a sex mismatched but 6/6 HLA-matched donor grafts [16]. Our cohort was similar to this as median age in our patients was 18 years and majority were complete HLA matched with their donors. These results suggest that in young hematopoietic stem cell transplant patients who are HLA matched, donor-recipient sex mismatch becomes insignificant to the outcome of the procedure.

Sex-mismatched transplant have traditionally been described to be associated with high incidence of TRM, particularly in patients receiving bone marrow as a source of stem cells [17]. In our patients, the TRM of patients receiving a sex-mismatched transplant was higher (40\%) than the same sex group. Previous studies have reported similar results for example, Gallardo et al. concluded that a combination of female donor and male recipient leads to increased risk of GvHD, higher TRM and lower OS [18].

In both the groups of our study, the OS was similar i.e. approximately 56\%. In 2015, Kongtim et al. reported in a group of 174 patients, female to male transplant procedures affected survival due to increase in nonrelapse mortality of $23.2 \%$ [19]. Nannya et al. have also reported similar results with a hazard ratio of 1.84 in female to male 
transplants [20]. Our results are in contrast to these studies and others reported in literature. The explanation to this could be attributed to the fact that our main clinical indications of performing stem cell transplant include $\beta$ thalassemia major and aplastic anemia. While in the western population, the main indication is leukemia, indicating a disparate study population. Furthermore, we have used peripheral blood stem cells as the major source of graft, while in both the studies mentioned above, the poor outcome was associated with the use of bone marrow stem cells. Also, as reported by us previously [13], there is a decreased incidence of GvHD in our population, therefore decreasing the non relapse mortality and subsequently leading to increased survival. Our data indicates that there was no difference in non relapse mortality between patients with or without GvHD in both groups. This is likely because, in our cohort, factors other than GvHD have caused morbidity and mortality in both groups. These factors include organ toxicities secondary to chemotherapy, sepsis and sinusoidal obstructive syndrome. Although this is the first study from Pakistan to report the outcome of sex match/mismatch transplant, a major limitation is its retrospective nature and heterogeneity of the cohort.

\section{Conclusion}

After HLA matching, there are several factors to consider when selecting a donor for hematopoietic stem cell transplant. Our study showed no correlation between sex match versus mismatch transplants with respect to GvHD and OS. We conclude that sex of the donor should not be considered in the donor selection algorithm until we have a better insight into the biology of sex-based alloreactivity.

\section{Summary points}

- Donor sex and parity remain to be the most debatable factors to determine the outcome of allogeneic stem cell transplant.

- Increased graft-versus-host disease (GVHD) in sex-mismatched transplants leads to decreased risk of relapse with increased overall survival.

- All patients in our cohort received a myeloablative conditioning regimen.

- Our study showed an increased transplant related mortality (40\%) in sex-mismatched transplant, the main cause of which was not GvHD.

- Mortality due to disease relapse was higher in sex-matched group.

- There was no statistically significant difference in both groups with respect to transplant-related mortality due to GvHD.

- The overall survival at 1 year was similar in both groups.

\section{Financial \& competing interests disclosure}

The authors have no relevant affiliations or financial involvement with any organization or entity with a financial interest in or financial conflict with the subject matter or materials discussed in the manuscript. This includes employment, consultancies, honoraria, stock ownership or options, expert testimony, grants or patents received or pending, or royalties.

No writing assistance was utilized in the production of this manuscript.

\section{Ethical conduct of research}

The authors state that they have obtained appropriate institutional review board approval or have followed the principles outlined in the Declaration of Helsinki for all human or animal experimental investigations. In addition, for investigations involving human subjects, informed consent has been obtained from the participants involved.

\section{Open access}

This work is licensed under the Attribution-NonCommercial-NoDerivatives 4.0 Unported License. To view a copy of this license, visit http://creativecommons.org/licenses/by-nc-nd/4.0/

\section{References}

Papers of special note have been highlighted as: • of interest

1. Klingebiel T, Cornish J, Labopin M et al. Results and factors influencing outcome after fully haploidentical hematopoietic stem cell transplantation in children with very high-risk acute lymphoblastic leukemia: impact of center size: an analysis on behalf of the acute leukemia and pediatric disease working parties of the European blood and marrow transplant group. Blood 115(17), 3437-3446 (2010). 
2. Morishima Y, Sasazuki T, Inoko H et al. The clinical significance of human leukocyte antigen (HLA) allele compatibility in patients receiving a marrow transplant from serologically HLA-A, HLA-B, and HLA-DR matched unrelated donors. Blood 99(11), 4200-4206 (2002).

3. Socie G, Ritz J. Current issues in chronic graft-versus-host disease. Blood 124(3), 374-384 (2014).

4. Remberger M, Kumlien G, Aschan J et al. Risk factors for moderate-to-severe chronic graft-versus-host disease after allogeneic hematopoietic stem cell transplantation. Biol. Blood Marrow Transplant. 8(12), 674-682 (2002).

5. Riddell SR, Murata M, Bryant S, Warren EH. Minor histocompatibility antigens-targets of graft versus leukemia responses. Int. J. Hematol. 76(Suppl. 2), 155-161 (2002).

6. Warren EH, Gavin M, Greenberg PD, Riddell SR. Minor histocompatibility antigens as targets for T-cell therapy after bone marrow transplantation. Curr. Opin. Hematol. 5(6), 429-433 (1998).

7. Mutis T, Goulmy E. Hematopoietic system-specific antigens as targets for cellular immunotherapy of hematological malignancies. Semin. Hematol. 39(1), 23-31 (2002).

8. Flowers ME, Pepe MS, Longton G et al. Previous donor pregnancy as a risk factor for acute graft-versus-host disease in patients with aplastic anaemia treated by allogeneic marrow transplantation. Br. J. Haematol. 74(4), 492-496 (1990).

- Parity of female donors influenced the frequency of graft-versus-host disease (GvHD) in stem cell transplant recipients.

9. Atkinson K, Farrell C, Chapman G, Downs K, Penny R, Biggs J. Female marrow donors increase the risk of acute graft-versus-host disease: effect of donor age and parity and analysis of cell subpopulations in the donor marrow inoculum. Br. J. Haematol. 63(2), 231-239 (1986).

10. Bross DS, Tutschka PJ, Farmer ER et al. Predictive factors for acute graft-versus-host disease in patients transplanted with HLA-identical bone marrow. Blood 63(6), 1265-1270 (1984).

11. Randolph SS, Gooley TA, Warren EH, Appelbaum FR, Riddell SR. Female donors contribute to a selective graft-versus-leukemia effect in male recipients of HLA-matched, related hematopoietic stem cell transplants. Blood 103(1), 347-352 (2004).

12. Gratwohl A, Hermans J, Niederwieser D et al. Female donors influence transplant-related mortality and relapse incidence in male recipients of sibling blood and marrow transplants. Hematol. J. 2(6), 363-370 (2001).

13. Ali N, Adil SN, Shaikh MU, Moosajee M, Masood N. Outcome of match related allogeneic stem cell transplantation procedures performed from 2004 till 2011. Exp. Hematol. Oncol. 1(1), 13 (2012).

14. Urbano-Ispizua A, Rozman C, Pimentel P et al. Risk factors for acute graft-versus-host disease in patients undergoing transplantation with CD34+ selected blood cells from HLA-identical siblings. Blood 100(2), 724-727 (2002).

15. Loren AW, Bunin GR, Boudreau C et al. Impact of donor and recipient sex and parity on outcomes of HLA-identical sibling allogeneic hematopoietic stem cell transplantation. Biol. Blood Marrow Transplant. 12(7), 758-769 (2006).

16. Friedrich P, Guerra-Garcia P, Stetson A, Duncan C, Lehmann L. Young female donors do not increase the risk of graft-versus-host disease or impact overall outcomes in pediatric HLA-matched sibling hematopoietic stem cell transplantation. Biol. Blood Marrow Transplant. 24(1), 96-102 (2018).

- Findings correlate with our study conclusion.

17. van Halteren AG, Dierselhuis MP, Netelenbos T, Fechter M. Donor parity no longer a barrier for female-to-male hematopoietic stem cell transplantation. Chimerism 5(2), 56-58 (2014).

- Findings correlate with our study conclusion.

18. Gallardo D, Perez-Garcia A, de la Camara R et al. Clinical outcome after sex-mismatched allogeneic stem cell transplantation from human lymphocyte antigen-identical sibling donors: influence of stem cell source. Leukemia 20(8), 1461-1464 (2006).

- Shows increased frequency of GvHD in sex mismatched transplant while our study showed no correlation.

19. Kongtim P, Di Stasi A, Rondon G et al. Can a female donor for a male recipient decrease the relapse rate for patients with acute myeloid leukemia treated with allogeneic hematopoietic stem cell transplantation? Biol. Blood Marrow Transplant. 21(4), 713-719 (2015).

20. Nannya Y, Kataoka K, Hangaishi A, Imai Y, Takahashi T, Kurokawa M. The negative impact of female donor/male recipient combination in allogeneic hematopoietic stem cell transplantation depends on disease risk. Transpl. Int. 24(5), 469-476 (2011). 